\title{
Effect of Age and Sex on Histomorphometrical Characteristics of Two Muscles of Laticauda Lambs
}

\author{
Salvatore Velotto ${ }^{\mathrm{a}}$, Ettore Varricchio ${ }^{\mathrm{b}}$, Maria Rosa Di Prisco ${ }^{\mathrm{a}}$, Tommaso Stasi ${ }^{\mathrm{a}}$ \\ and Antonio Crasto ${ }^{\mathrm{a}}$ \\ aUniversity of Study of Naples Federico II, Department of Soil, Plant, Environmental and Animal Production \\ Sciences, Faculty of Agraria Via Università, Portici, Italy \\ bUniversity of Study of Sannio, Department of Biological and Environmental Science, Faculty of Science \\ MM.FF.NN., Benevento, Italy \\ Received January 15, 2009 \\ Accepted June 30, 2009
}

\begin{abstract}
The aim of the present experiment was to determine the effect of sex and age on histochemical and morphometric characteristics of muscle fibres (myocytes) in lambs born by single, twin, triplet and quadruplet birth.

Thirty lambs were slaughtered at 60 days of age; thirty were weaned at 60 days and fed until 120 days with flakes (60\%) and food supplements, and then slaughtered. Muscle tissues were obtained from two muscles, namely $\mathrm{m}$. semitendinosus and $\mathrm{m}$. longissimus dorsi of all lambs. For each fibre type, area perimeter and diameter (maximum and minimum) were measured and slow-twitch oxidative fibres, fast-twitch glycolytic fibres, fast-twitch oxidative-glycolytic fibres were histochemically differentiated. The muscles were stained for myosin ATPase, and succinic dehydrogenase. At 60 days, females had fibres larger than males, whereas the opposite was observed at 120 days. Besides, at 60 days, the lambs born by single birth had fibres larger than those born by multiple birth, whereas the opposite was observed at 120 days. Single lambs were heavier than twin lambs and multiple lambs. Fast-twitch glycolytic fibres had the largest size, followed by slow-twitch oxidative and fast-twitch oxidative glycolytic fibres. The dimensions of fibre types in $\mathrm{m}$. longissimus dorsi were larger than in $\mathrm{m}$. semitendinosus $(P<0.001)$. These muscle fibre characteristics are thought to be important factors influencing meat quality, which is often related to metabolic and contractile properties as determined by the muscle fibre type distribution.
\end{abstract}

Birth type, postnatal development, lamb, histochemistry, nutrition, muscle fibres

The Laticauda originated probably from the Northern African sheep, Berbera or Barbaresca, and it got the present characteristics thanks to subsequent crossbreeds with the sheep from the Apennines, the typical one from Southern Italy. Particularly, Laticauda is bred in the country of Benevento and Avellino and during the last years the head number has increased. This breed is traditionally reared in hilly farm pasture predominantly in sedentary breeding groups and the most common farming system is the "family farm type". Laticauda is a dual-purpose breed with the ability to produce good amount of milk and meat. Meat quality is affected by numerous factors including the growth stage and differentiation of skeletal muscle fibre types. The physiological differentiation of muscle fibres is a dynamic equilibrium which can vary during growth or as a response to the muscle work rate. Guth and Yellin (1971) noticed that muscle fibres continuously change during the animal's life as a functional demand adaptation and that the fibre type only reflects the fibre constitution at a certain moment. Henkel (1991) suggested muscle histochemistry as a tool for quantifying the effect of different treatments on the size of muscle fibres. In this study we have defined the skeletal muscle fibre populations of lambs by using different methods of m-ATPase and we have analyzed the postnatal development of these fibre populations between 60 and 120 days of age. Muscle fibre type may be classified based on the enzymatic activity; in this study the following nomenclature is used for myofibre types:

Address for correspondence:

Dr. Salvatore Velotto, $\mathrm{PhD}$.

Department of Soil, Plant, Environmental and Animal Production Sciences

Faculty of Agraria, University of Study of Naples "Federico II"

Via Università 133, 80055, Portici (NA), Italy
Phone: +390812539269-264

Fax: +390817762886

E-mail: velotto@unina.it

http://www.vfu.cz/acta-vet/actavet.htm 
FG (fast-contracting with glycolytic metabolism) or IIB fibres; type SO (slow-contracting with oxidative metabolism) or I fibres and FOG (fast contracting-with glycolytic-oxidative metabolism) or IIA fibres. The information obtained by the distribution of different fibre types, their number and diameter and/or area, represent an element of paramount importance for the determination of some basis characteristics (morphological and functional) of the muscle that have great influence on some aspects of meat quality. Our study also intends to assess probable correlation between the birth type and weight. Particularly the lambs born by single birth had higher weight than lambs born by multiple births and the degree to which it was reduced was influenced by postnatal nutrition (Greenwood et al. 2000).

\section{Materials and Methods}

We used sixty lambs (30 males and 30 females) coming from a farm located in Caserta (Italy) that were slaughtered at 60 and 120 days. The slaughter house had EEC mark with reference to rules 852/853/854/2004; 2076/2005; 1069/2009. The animals were treated according to the guidelines of the European Community on the treatment of experimental animals (Reg. CE 1/2005; directives 74/577/EEC; Act 4392 August 1978). They were born by single, twin, triplet and quadruplet births and were fed mother's milk until 60 days of age. All of the ovines had passed the obligatory health tests and had the characteristic pattern of the species.

Lambs were identified and weighed at birth, and the weight was checked weekly until the end of the study. The time periods for the slaughter of the lambs during the postnatal development to obtain the muscle samples were 60 and 120 days after the birth. We obtained the muscle samples surgically, and we used m. semitendinosus (St) and $\mathrm{m}$. longissimus dorsi (Ld). To avoid possible morphological and morphometric alterations of the fibres, the samples were frozen during the first hour after the animal's slaughter in 2-methylbutane cooled in liquid nitrogen. Transverse serial sections $(8 \mu \mathrm{m})$ were cut in a cryostat at $-20^{\circ} \mathrm{C}$. The sections were stained histochemically for myosin ATPase (m-ATPase shows the muscular contraction) and succinic dehydrogenase (SDH shows the fibres metabolism) simultaneously on the same muscular fibres (Padykula and Herman 1955; Nachlas et al. 1957; Barany 1967; Edstrom and Kugelberg 1968; Guth and Samaha 1970; Solomon and Dunn 1988; Velotto et al. 2005). The method used for the combined histochemical staining (acid m-ATPase + SDH) consisted of different phases. Acid pre-incubation was performed at room temperature for $20 \mathrm{~min}$ and was always followed by two 1-min rinses in $\mathrm{CaCl}_{2}$ in tris hydroxymethyl aminomethane buffer rinses solution. Nitro blue tetrazolium (NBT) incubation was performed for the detection of SDH activity at $37^{\circ} \mathrm{C}$ for $20 \mathrm{~min}$ followed by two rinses in distilled water. For the myofibrillar (acid) ATPase portions, the procedure was performed at $37^{\circ} \mathrm{C}$ at $\mathrm{pH} 9.4$ for $60 \mathrm{~min}$ along with two times for five minutes in $\mathrm{CaCl}_{2}$ solution and incubation for $5 \mathrm{~min}$ in $\mathrm{CoCl}_{2}$ solution. Finally, ammonium sulphide staining of the acid ATPase procedure was performed. Cover slips were placed over the stained tissue sections and fixed in place using glycerol jelly. Additional serial sections were also histochemically stained for detection of basic m-ATPase and SDH activities. The basic m-ATPase method consisted of different phases. Sodium-cacodylate and sucrose solutions were used for incubation for $5 \mathrm{~min}$ followed by two 1-min rinses in $\mathrm{CaCl}_{2}$ in tris hydroxymethyl aminomethane buffer rinse solution. Sigma 221 and $\mathrm{CaCl}_{2}$ solutions were used for 10 min at the range of $\mathrm{pH}$ 10.3-10.5 followed by two 1-min rinses in $\mathrm{CaCl}_{2}$ and tris hydroxymethyl aminomethane buffer (Merck \& Co USA) rinse solution. For the myofibrillar (acid) ATPase portions, the procedure was performed at $37^{\circ} \mathrm{C}$ at a pH of 9.4 for 50 min along with one 30 -s rinse in $\mathrm{CaCl}_{2}$ solution and incubation for 3 min in $\mathrm{CoCl}_{2}$ solution. Finally, ammonium sulphide staining of the acid ATPase procedure was performed. Cover slips were placed over the stained tissue sections and fixed in place using glycerol jelly. The SDH method was used for the second control procedure and consisted of different phases. Incubation in NBT at $37^{\circ} \mathrm{C}$ was performed for $40 \mathrm{~min}$ followed by two rinses in distilled water. Finally, formaldehyde solution was used for $10 \mathrm{~min}$. Cover slips were placed over the stained tissue sections, and fixed in place using glycerol jelly. Morphometric analyses were carried out using an interactive image analysis system (Leica CM 1100). The parameter of minimum diameter was selected as measurement of the fibre diameter to avoid possible errors because of tilted sections. In each muscle section at least 150 fibres of each type were analyzed using random fields. The average fibre size (area, perimeter, maximum and minimum diameter) was calculated. Data were processed by analysing the variances and means were estimated by following the general linear model (Proc GLM; SAS, 1992) in which the factors considered are fixed, and the effect of the other factors is expressed as deviation from the general average $(\mu)$.

The model used was:

$\mathrm{y}_{\mathrm{ijklm}}=\mu+\mathrm{Sex}_{\mathrm{i}}+\mathrm{Bt}_{\mathrm{j}}+\mathrm{Mu}_{\mathrm{k}}+\mathrm{Ft}_{1}+(\mathrm{sex} * \mathrm{Ft})_{\mathrm{il}}+(\mathrm{Bt} * \mathrm{Ft})_{\mathrm{jl}}+(\mathrm{Mu} * \mathrm{Ft})_{\mathrm{kl}}+\varepsilon \mathrm{ijklm}$.

$\mathrm{y}_{\mathrm{j} j \mathrm{kl} \mathrm{m}}=$ value of relative observation to the $1_{\mathrm{mo}}$ fibre type of the $\mathrm{k}_{\mathrm{mo}}$ muscle; of the $\mathrm{m}_{\mathrm{mo}}$ subject of $\mathrm{i}_{\mathrm{mo}}$ sex, born of $\mathrm{j}_{\mathrm{mo}}$ birth type.

$\operatorname{Sex}_{i}=$ fixed effect of the $i_{m o} \operatorname{sex}(I=1,2)$.

$\mathrm{Btj}=$ fixed effect of the $\mathrm{J}_{\mathrm{mo}}^{\mathrm{mo}}$ birth type $(\mathrm{j}=1,2,3,4)$.

$\mathrm{Mu}_{\mathrm{k}}=$ fixed effect of the $\mathrm{k}_{\mathrm{m}}$ muscle $(\mathrm{k}=1,2)$.

$\mathrm{Ft}_{1}=$ fixed effect of the $1_{\mathrm{mo}}$ fibre type $(1=1,2,3)$.

$(\mathrm{Sex} * \mathrm{Ft})_{\mathrm{il}}=$ fixed effect of the $\mathrm{i}_{\mathrm{mo}}$ sex with the $1_{\mathrm{mo}}$ fibre type. 
$(\mathrm{Bt} * \mathrm{Ft})_{\mathrm{il}}=$ fixed effect of the $\mathrm{j}_{\mathrm{mo}}$ birth type with the $\mathrm{l}_{\mathrm{mo}}$ fibre type.

$(\mathrm{Mu} * \mathrm{Ft})_{\mathrm{kl}}=$ fixed effect of the $\mathrm{k}_{\mathrm{mo}}$ muscle with the $1_{\mathrm{mo}}$ fibre type.

$\varepsilon_{\mathrm{ijklm}}=$ residual error.

Significance between the mean values was evaluated using Student's $t$-test.

\section{Results}

The birth weight was higher in lambs born by single birth than in lambs born by multiple births. Lambs born by single birth and slaughtered at 60 days after birth weighed more than those born by twin birth $(5036.4 \mathrm{~g}$ vs. $4243.5 \mathrm{~g} ; P<0.05)$ triplet birth $(5036.4 \mathrm{~g}$ vs. 2855.7 $\mathrm{g} ; P<0.01)$ and quadruplet birth $(5036.4 \mathrm{~g}$ vs. $1986.3 \mathrm{~g} ; P<0.01)$. A similar trend was noticed at 120 days after birth. Lambs born by single and multiple birth slaughtered at 60 days showed similar average daily increase in weight, even if lambs born by triplet birth showed a higher increment than those born by multiple births or single birth. At 120 days the daily increase of weight was highest in lambs born by triplet birth than those born by twin birth $(112 \mathrm{~g} / \mathrm{d}$ vs. $68.4 \mathrm{~g} / \mathrm{d} ; P<0.05)$. Lambs slaughtered at 60 days and fed mother's milk only showed a similar live weight in all birth types considered, whereas the lambs slaughtered at 120 days and born by triplet birth showed weights higher than those born by twin births $(22.12 \mathrm{~kg}$ vs. $18.58 \mathrm{~kg} ; P<0.05)$ and single birth $(22.12 \mathrm{~kg}$ vs. $19.08 \mathrm{~kg}$; $P<0.05)$. The histochemical staining results of muscle fibre types in the lambs were based on combined m-ATPase reactions, after acid ( $\mathrm{pH}$ range 4.35-4.4) and alkaline ( $\mathrm{pH}$ range 10.3-10.5) pre-incubations in St and Ld muscles. The muscle fibre types identified in the lambs could be classified in three types (Plate I, Figs 1, 2, 3, 4, 5, 6 and Plate II, Fig. 7): type I or SO (slow-twitch oxidative), type IIB or FG (fast-twitch glycolytic) were moderately alkaline and acid-negative fibres, and type IIA or FOG (fast-twitch oxidative-glycolytic) were highly alkaline and acid-negative fibres.

Table 1. Value relative to the experimental factors considered at 60 days and at 120 days

\begin{tabular}{|c|c|c|c|c|}
\hline \multirow{3}{*}{$F^{(1)}$} & \multicolumn{4}{|c|}{ Variable } \\
\hline & \multirow{2}{*}{ Area } & \multirow{2}{*}{ Perimeter } & \multicolumn{2}{|c|}{ Diameter } \\
\hline & & & Minimum & Maximum \\
\hline \multicolumn{5}{|c|}{60 days of age } \\
\hline Sex & $136.42 * * *$ & $74.59 * * *$ & $160.02 * * *$ & $27.14 * * *$ \\
\hline Birth type, Bt & $30.48 * * *$ & $41.13 * * *$ & $11.95 * * *$ & $56.18^{* * *}$ \\
\hline Muscle, $\mathrm{Mu}$ & $905.32 * * *$ & $1072.16^{* * *}$ & $633.48 * * *$ & $1068.39 * * *$ \\
\hline Fibre type, Ft & $355.63 * * *$ & $350.49 * * *$ & $267.59 * * *$ & $321.25^{* * *}$ \\
\hline Sex*Ft & $21.57 * * *$ & $16.89 * * *$ & $14.16^{* * *}$ & $13.89 * * *$ \\
\hline $\mathrm{Bt}^{*} \mathrm{Ft}$ & $11.18^{* * *}$ & $9.72 * * *$ & $7.69 * * *$ & $7.51 * * *$ \\
\hline $\mathrm{Mu}^{*} \mathrm{Ft}$ & $54.09 * * *$ & $39.16^{* * *}$ & $31.85 * * *$ & $34.51 * * *$ \\
\hline \multicolumn{5}{|c|}{120 days of age } \\
\hline Sex & $152.58 * * *$ & $150.46^{* * *}$ & $67.82 * * *$ & $168.7 * * *$ \\
\hline Birth type, Bt & $52.20 * * *$ & $37.51 * * *$ & $42.21 * * *$ & $31.89 * * *$ \\
\hline Muscle, $\mathrm{Mu}$ & $785.32 * * *$ & $979.62 * * *$ & $570.53 * * *$ & $1005.02 * * *$ \\
\hline Fibre type, Ft & $77.81 * * *$ & $75.23 * * *$ & $85.12 * * *$ & $60.43 * * *$ \\
\hline Sex*Ft & $6.01 *$ & $6.92 * * *$ & $4.25^{*}$ & $5.98 * *$ \\
\hline $\mathrm{Bt} * \mathrm{Ft}$ & $18.79 * * *$ & $16.92 * * *$ & $16.15 * * *$ & $12.42 * * *$ \\
\hline $\mathrm{Mu}^{*} \mathrm{Ft}$ & $27.48 * * *$ & $26.32 * * *$ & $26.03 * * *$ & $21.13 * * *$ \\
\hline
\end{tabular}

(1) $*=P<0.05 ; * *=P<0.01 ; * * * P<0.001$

In the lambs, the alkaline fibres (IIA) were highly oxidative and highly glycolytic, thus corresponding to type FOG fibres. However, some of the fibres had a weak glycolytic activity. The alkaline fibres (IIB) were mainly oxidative-negative and highly glycolytic, 
Table 2. Mean value (avg) and variation coefficient (v.c., \%) of morphometric characteristics of fibre types in the males and females as related to age

\begin{tabular}{|c|c|c|c|c|c|c|c|c|}
\hline \multirow{3}{*}{ Fibre Types } & \multirow{2}{*}{\multicolumn{2}{|c|}{ Area $/ \mu m^{2}$}} & \multirow{2}{*}{\multicolumn{2}{|c|}{ Perimeter $/ \mu \mathrm{m}$}} & \multicolumn{4}{|c|}{ Diameter/ $\mu \mathrm{m}$} \\
\hline & & & & & \multicolumn{2}{|c|}{ minimum } & \multicolumn{2}{|c|}{ maximum } \\
\hline & avg & v. c., $\%$ & avg & v. c., $\%$ & avg & v. c., $\%$ & avg & v. c., $\%$ \\
\hline \multicolumn{9}{|c|}{60 days of age } \\
\hline \multicolumn{9}{|c|}{ Males } \\
\hline FG & 1008.27 & 56 & 131.19 & 27 & 30.87 & 30 & 50.67 & 30 \\
\hline $\mathrm{FOG}$ & 705.28 & 51 & 110.64 & 24 & 25.88 & 27 & 42.80 & 26 \\
\hline $\mathrm{SO}$ & 807.18 & 53 & 115.76 & 26 & 27.79 & 30 & 44.19 & 29 \\
\hline \multicolumn{9}{|c|}{ Females } \\
\hline FG & 1095.02 & 58 & 134.90 & 30 & 32.59 & 33 & 51.45 & 31 \\
\hline FOG & 744.30 & 55 & 112.09 & 26 & 27.05 & 31 & 42.75 & 27 \\
\hline $\mathrm{SO}$ & 987.33 & 59 & 125.64 & 30 & 31.06 & 34 & 47.21 & 30 \\
\hline \multicolumn{9}{|c|}{120 days of age } \\
\hline \multicolumn{9}{|c|}{ Males } \\
\hline FG & 1294.45 & 66 & 144.88 & 35 & 34.56 & 34 & 55.72 & 38 \\
\hline FOG & 956.12 & 64 & 124.83 & 33 & 29.43 & 32 & 48.02 & 36 \\
\hline SO & 1173.13 & 63 & 135.88 & 33 & 32.77 & 32 & 51.88 & 36 \\
\hline \multicolumn{9}{|c|}{ Females } \\
\hline FG & 1029.84 & 59 & 131.46 & 30 & 32.16 & 31 & 49.91 & 32 \\
\hline FOG & 777.07 & 59 & 114.41 & 29 & 27.67 & 31 & 43.56 & 31 \\
\hline SO & 1036.16 & 61 & 130.14 & 31 & 31.86 & 34 & 49.22 & 33 \\
\hline
\end{tabular}

$\mathrm{FG}=$ fast glycolytic fibres, $\mathrm{FOG}=$ fast glycolytic oxidative fibres; $\mathrm{SO}=$ slow oxidative fibres

which would correspond to type FG fibres. However, some of the fibres had highly oxidative activity. The percentage of FOG fibres in the Ld and St muscles were $45 \%$ and $38 \%$, respectively, at 60 days and $52 \%$ and $44 \%$, respectively, at 120 days. The FOG fibres were characterized by a more versatile oxidative-glycolytic metabolism, according to the necessity to obtain energy for the contraction. At 120 days an increased number of FOG fibres was noticed in the St and Ld muscles ( $+6 \%$ and $+7 \%$ respectively) accompanied by a reduction of SO fibre (-5\% and $-5 \%$ respectively). We studied the fibre type in males and females in order to detect differences in the birth type. In the first group of lambs $(60$ days) the females had larger fibres than the males, whereas the opposite was observed in the other group (120 days). The results of the analysis of variance showed significant interactions between muscle $\times$ fibre type, birth type $\times$ fibre type, sex $\times$ fibre type (Table 1$)$. The difference between females and males (fibre area at 60 days) was $8 \%$ for FG (1095.02 vs. $1008.27, P<0.001), 5 \%$ for FOG (744.30 vs. $705.28, P<0.01)$ and $18 \%$ SO $(987.33$ vs. $807.18, P<0.001)$. At 120 days the males had larger fibres than females, the differences between males and females were $20 \%$ for FG (1294.45 vs. $1029.84, P<0.001), 18 \%$ for FOG (956.12 vs. $777.07, P<0.001)$, and $11 \%$ for SO (1173.13 vs. $1036.16, P<0.001)$ (Table 2). With respect to the birth type, lambs born by single birth and slaughtered at 60 days had greater fibres than those born by multiple births. Particularly the difference between single and quadruplet birth (fibre area) was 28\% for FG (1236.91 vs. 887.77, $P<0.001), 24 \%$ for FOG (812.83 vs. $616.68, P<0.001)$ and $12 \%$ for SO (943.56 vs. 830.01, $P<0.001$ ) (Table 3). Lambs born by double and triplet birth and slaughtered at 120 days had larger fibres than those born by single birth. The differences between twin and single births in fibre area were non-significant for $\mathrm{FG}$, on the contrary were $26 \%$ for $\mathrm{FOG}(901.10$ vs. $662.24, P<0.001)$, and $15 \%$ for SO (1052.2 vs. 877.74, $P<0.001)$. The differences between triplet and single birth in fibre area were non-significant for FG on the contrary 
Table 3. Mean value (avg) and variation coefficient (v.c.,\%) of morphometric characteristics of fibre types for birth type as related to age

\begin{tabular}{|c|c|c|c|c|c|c|c|c|}
\hline \multirow{3}{*}{ Fibre Types } & \multirow{2}{*}{\multicolumn{2}{|c|}{ Area $/ \mu \mathrm{m}^{2}$}} & \multirow{2}{*}{\multicolumn{2}{|c|}{ Perimeter $/ \mathrm{mm}$}} & \multicolumn{4}{|c|}{ Diameter $/ \mathrm{mm}$} \\
\hline & & & & & \multicolumn{2}{|c|}{ minimum } & \multicolumn{2}{|c|}{ maximum } \\
\hline & avg & v. c., $\%$ & avg & v. c., $\%$ & avg & v. c., $\%$ & avg & v. c., $\%$ \\
\hline \multicolumn{9}{|c|}{60 days of age } \\
\hline \multicolumn{9}{|c|}{ Single birth } \\
\hline $\mathrm{FG}$ & 1236.91 & 41 & 148.15 & 24 & 34.58 & 25 & 57.62 & 27 \\
\hline FOG & 812.83 & 41 & 129.44 & 22 & 27.60 & 24 & 46.67 & 25 \\
\hline $\mathrm{SO}$ & 943.50 & 49 & 124.03 & 25 & 29.74 & 26 & 47.51 & 27 \\
\hline \multicolumn{9}{|c|}{ Double birth } \\
\hline $\mathrm{FG}$ & 1002.42 & 53 & 130.35 & 26 & 31.20 & 31 & 49.88 & 29 \\
\hline FOG & 723.21 & 49 & 111.09 & 24 & 26.70 & 29 & 42.39 & 25 \\
\hline SO & 898.98 & 63 & 119.71 & 27 & 29.33 & 35 & 45.52 & 30 \\
\hline \multicolumn{9}{|c|}{ Triplet birth } \\
\hline FG & 1052.45 & 66 & 132.10 & 31 & 31.39 & 35 & 50.73 & 32 \\
\hline FOG & 746.45 & 59 & 112.46 & 28 & 26.91 & 31 & 43.03 & 29 \\
\hline $\mathrm{SO}$ & 856.51 & 57 & 118.82 & 29 & 28.75 & 32 & 45.89 & 30 \\
\hline \multicolumn{9}{|c|}{ Quadruplet birth } \\
\hline FG & 887.77 & 53 & 121.58 & 26 & 29.74 & 29 & 46.05 & 28 \\
\hline FOG & 616.68 & 48 & 102.48 & 23 & 24.67 & 26 & 38.98 & 24 \\
\hline SO & 830.01 & 50 & 120.08 & 23 & 29.85 & 28 & 44.86 & 23 \\
\hline \multicolumn{9}{|c|}{120 days of age } \\
\hline \multicolumn{9}{|c|}{ Single birth } \\
\hline FG & 1080.16 & 51 & 134.70 & 24 & 33.59 & 27 & 50.92 & 25 \\
\hline FOG & 662.24 & 44 & 107.34 & 22 & 25.64 & 25 & 40.91 & 24 \\
\hline $\mathrm{SO}$ & 877.74 & 42 & 122.74 & 22 & 29.53 & 24 & 46.66 & 23 \\
\hline \multicolumn{9}{|c|}{ Double birth } \\
\hline FG & 1192.67 & 64 & 141.46 & 32 & 33.46 & 33 & 54.41 & 35 \\
\hline FOG & 901.10 & 61 & 123.51 & 31 & 29.16 & 31 & 47.62 & 33 \\
\hline $\mathrm{SO}$ & 1052.02 & 63 & 130.46 & 32 & 31.58 & 34 & 49.73 & 34 \\
\hline \multicolumn{9}{|c|}{ Triplet birth } \\
\hline FG & 1115.05 & 68 & 138.31 & 35 & 33.09 & 34 & 53.11 & 38 \\
\hline FOG & 994.26 & 66 & 128.01 & 33 & 30.83 & 32 & 48.83 & 37 \\
\hline $\mathrm{SO}$ & 1332.95 & 59 & 145.85 & 31 & 35.83 & 31 & 55.26 & 35 \\
\hline \multicolumn{9}{|c|}{ Quadruplet birth } \\
\hline FG & 932.12 & 56 & 127.66 & 27 & 30.53 & 30 & 48.35 & 29 \\
\hline FOG & 647.51 & 50 & 107.60 & 24 & 25.90 & 27 & 40.93 & 25 \\
\hline $\mathrm{SO}$ & 871.51 & 52 & 126.10 & 24 & 31.34 & 29 & 47.10 & 24 \\
\hline
\end{tabular}

$\mathrm{FG}=$ fast glycolytic fibres, $\mathrm{FOG}=$ fast glycolytic oxidative fibres; $\mathrm{SO}=$ slow oxidative fibres.

were $33 \%$ for FOG (994.26 vs. 662.24, $P<0.001)$, and 34\% for SO (1332.95 vs. 877.74 , $P<0.001)$. Non-significant differences were noticed between single and quadruplet birth in fibre area for FOG and SO. The other morphometric indicators showed a similar trend. In agreement with Velotto et al. (2005) who noticed a similar difference in the caput longum tricipitis brachii of the lamb, the dimensions of FOG fibres in Ld at 60 and 120 days were larger than in St (Table 4). At 60 and 120 days no significant differences were noticed between $\mathrm{Ld}$ and St muscles in the fibre area for SO. FG fibres were larger in Ld muscle at 60 days; however, the opposite was observed at 120 days. 
Table 4. Mean value (avg) and variation coefficient (v.c.,\%) of morphometric characteristics of fibre types in muscles under study

\begin{tabular}{|c|c|c|c|c|c|c|c|c|}
\hline \multirow{3}{*}{ Fibre Types ${ }^{(1)}$} & \multirow{2}{*}{\multicolumn{2}{|c|}{ Area $/ \mu \mathrm{m}^{2}$}} & \multirow{2}{*}{\multicolumn{2}{|c|}{ Perimeter/mm }} & \multicolumn{4}{|c|}{ Diameter $/ \mathrm{mm}$} \\
\hline & & & & & \multicolumn{2}{|c|}{ minimum } & \multicolumn{2}{|c|}{ maximum } \\
\hline & avg & v.c., $\%$ & avg & v.c., $\%$ & avg & v.c., $\%$ & avg & v.c., $\%$ \\
\hline \multicolumn{9}{|c|}{60 days of age } \\
\hline \multicolumn{9}{|c|}{$\mathrm{Ld}$} \\
\hline FG & 906.10 & 50 & 119.65 & 24 & 28.55 & 28 & 45.92 & 25 \\
\hline FOG & 620.37 & 42 & 100.31 & 19 & 23.87 & 23 & 38.48 & 21 \\
\hline $\mathrm{SO}$ & 757.48 & 60 & 106.44 & 29 & 26.07 & 33 & 40.18 & 29 \\
\hline \multicolumn{9}{|c|}{$\mathrm{St}$} \\
\hline FG & 808.962 & 55 & 116.82 & 24 & 28.512 & 33 & 43.241 & 26 \\
\hline FOG & 577.995 & 50 & 111.642 & 22 & 23.804 & 28 & 39.96 & 24 \\
\hline $\mathrm{SO}$ & 798.083 & 55 & 118.25 & 22 & 30.173 & 24 & 46.563 & 24 \\
\hline \multicolumn{9}{|c|}{120 days of age } \\
\hline \multicolumn{9}{|c|}{$\mathrm{Ld}$} \\
\hline FG & 1030.15 & 56 & 136.97 & 28 & 33.23 & 30 & 52.19 & 30 \\
\hline FOG & 725.89 & 46 & 116.71 & 23 & 28.18 & 26 & 44.40 & 25 \\
\hline $\mathrm{SO}$ & 905.59 & 59 & 126.47 & 29 & 30.94 & 33 & 47.95 & 29 \\
\hline \multicolumn{9}{|c|}{$\mathrm{St}$} \\
\hline FG & 1076.174 & 62 & 132.715 & 31 & 33.847 & 34 & 50.908 & 33 \\
\hline FOG & 691.218 & 64 & 108.746 & 27 & 27.566 & 32 & 41.052 & 31 \\
\hline $\mathrm{SO}$ & 906.576 & 55 & 123.717 & 27 & 31.47 & 27 & 47.344 & 30 \\
\hline
\end{tabular}

(1) $\mathrm{Ld}=\mathrm{m}$. longissimus dorsi $\mathrm{St}=\mathrm{m}$. semitendinosus

$\mathrm{FG}=$ fast glycolytic fibres, $\mathrm{FOG}=$ fast glycolytic oxidative fibres; $\mathrm{SO}=$ slow oxidative fibres

\section{Discussion}

The present study demonstrates that the distribution and size of different muscle fibre types are affected by species, breed, muscle type, sex, birth type and that they in turn seem to affect the quality of meat. The results of this study show that lambs born by single birth and fed mother's milk have higher weights and larger fibres than those born by multiple births. Ruttle (1971) demonstrated that type of birth had the greatest influence on the birth and weaning weight of early weaned lambs. Lambs born as singles weighed more at birth than lambs born as twins and triplets. Besides, lambs weaned at 3 months of age were heavier than lambs weaned at 2 months and this difference was highly significant. Cimen (2006) indicated that it is possible that poor nutrition (especially for dams with twin lambs) during early postnatal life imposes a permanent limitation on fibre production ability and fibre diameter of the lamb. After weaning, the muscle fibre development varied in relation to the birth type: FOG and SO fibres developed more in triplet births than in single births. The effect was due to the limited amount of milk for the lambs. This result is assumed that the effect of birth type takes after 60 days of development, when it was made weaning. We know that the muscle function influences the final percentage of muscle fibre type.

Our study highlights that Ld muscle shows a high percentage of FOG. Ld is the intermediate and largest of the continuations of the sacrospinalis. According to Briand et al. (1981) this muscle exhibits both high oxidative and high glycolytic activity. In the St muscle at 120 days it was possible to notice an increase of FOG fibres and a reduction of FG and SO fibres. Some studies (Ashmore et al. 1972; Suzuki et al. 1988) suggest that in sheep the percentage and distribution of the different types of 
fibres, classified by means of the m-ATPase technique, are genetically determined in the semitendinosus, triceps brachii and abdominal cutaneous muscles. However, the percentage of the m-ATPase fibre types changed after birth in the quadriceps muscle (White et al. 1978) and in the longissimus muscle (Moody et al. 1980). Velotto et al. (2005) studied the distribution of the three fibre types in two muscles of the Gentile of Puglia (caput longum $\mathrm{m}$. tricipitis brachii and $\mathrm{m}$. psoas major) and confirmed the high percentage of FOG fibres in both muscles considered. Our results show that the percentage of the fibres I, IIA, and IIB in the longissimus varies between day 60 and 120 of the development. Suzuki and Cassens (1983) analyzed in sheep the development of the fibres percentage in the growing serratus ventralis thoracis muscle. According to these authors, the number of type II fibres (IIA plus IIB) decreases from birth $(80 \%)$ until 4 weeks after birth (65\%) and remains constant until the end of development. However, type I fibres increase their number from birth (10\%) until 4-weeks old (35\%) but then the percentage is also constant. Our results in the longissimus dorsi muscle show that the percentage of IIA fibres increased between 60 and 120 days after birth, whereas the percentage of type IIB fibres decreased between 60 and 120 days after birth. However, in our study type I as the IIB one decreased during development.

The difference between our work and that of Suzuki and Cassens (1983) might be due to the fact that we studied different muscles. Some publications (Ashmore et al. 1972; Hawkins et al. 1985) suggest a transformation of the IIA fibres (of small size) into IIB fibres (of a bigger size) as an explanation for the increase of muscular size during the development. We think that the developmental course of oxidative and/or glycolytic fibres should be specifically tested in future works.

Some studies (Solomon et al. 1981) described different increases of percentages for certain aerobic fibres in the ovine longissimus muscle, and at 8 weeks after birth, Whipple and Koohmaraie (1992) found 48.6\% of oxidative fibres and $41.6 \%$ of glycolytic fibres in this muscle. With respect to the size of fibre types, our results show that in the lambs slaughtered at 60 days the dimensions of fibres in the females are larger than in the males. The opposite was observed for the lambs slaughtered at 120 days. It has been suggested (Hawkins et al. 1985) that the increase in the carcass fat content is related to an increase in the red fibre size. This study also relates the size of the muscular fibres to the slaughtered weight, race and sex of the animals. Suzuki et al. (1988) proposed that in sheep the size of the type I fibres is similar to the size of the type IIB fibres in the hip and thigh muscles, as well as in other muscles (Suzuki $1971 \mathrm{ab}$; Suzuki and Cassens 1983). They also indicated that in sheep the glycolytic fibres (white) are not always bigger than the oxidative fibres (red).

Our results confirm the large size of the fibres IIB and I and the smaller size of the IIA fibres. It is also noticeable that all three types of fibres identified with the m-ATPase technique significantly increased their size only between 60 and 120 days after birth. In summary, with the use of an appropriate m-ATPase technique, the two fast fibre types IIA and IIB can be separated histochemically in skeletal muscle of lambs, even at early stages of postnatal development. McCoard et al. (2001) observed that twin neonate lambs sacrificed at 20 days had lower body weights and muscle weights compared to single born lambs. Lower muscle weights in twins were associated with smaller myofibre cross-sectional areas and lower total nuclei numbers and myogenic precursor cell numbers $\times$ muscle in selected hind-limb muscles. These results indicate that myofibre hypertrophy in late gestation and early postnatal life is related to myogenic precursor cell number which may have important implications for growth potential of the growth-restricted fetus. In agreement with the previous study our results highlight that at 60 days the lambs born by twin birth and multiple birth have fibres smaller than the lambs born by single birth. Fibre area in the lambs increased $(P<0.01)$ with age 
in both oxidative and glycolytic fibres (Whipple and Koohmaraie 1992). Our study demonstrates that the $L d$ muscle has shown a significant development in FOG fibre type higher than in the $S t$ muscle at 60 and 120 days while the opposite was observed for FG and SO fibres types. The present research shows the evolution of muscle fibre characteristics in the period 60-120 days of life for lambs born by single and multiple births. Significant interaction among the considered factors highlighted with variance analysis discussed in the previous section demonstrates that age, sex and birth type influence the dimensions of the fibres and consequently the meat quality. Meat quality is a term used to describe a range of attributes of meat. However, it is now becoming clear that variation in other factors such as the muscle fibre type composition and the buffer capacity of the muscle together with the breed and nutritional status of the animals may also contribute to be observed variations in meat tenderness (Maltin et al. 2003).

\section{References}

Ashmore CR, Tompkins G, Doerr L 1972: Postnatal development of muscle fiber types in domestic animals. J Anim Sci 34: 37-41

Barany M, 1967: ATPase activity of myosin correlated with speed of muscle shortening. J Gen Physiol 50: 197218

Briand M, Talamant A, Briand Y, Monin G, Durand R 1981: Metabolic types of muscle in the aheep: I. Myosin ATPase, glycolytic, and mitochondrial enzyme activities. Eur J Appl Physiol 46: 347-358

Cimen M 2006: The Effect of Birth Type and Sex of Lambs on Fiber Diameter. J Agric Biol Sci 2: 509-511

Edstrom LE, Kugelberg E 1968: Histochemical composition, distribution of fibres and fatiguability of single motor units. Anterior tibial muscle of the rat. J Neurol Neurosurg and Psychiat 31: 424-433

Greenwood PL, Hunt AS, Hermanson JW, Bell AW 2000: Effects of birth weight and postnatal nutrition on neonatal sheep: II Skeletal muscle growth and development. J Anim Sci 78: 50-61

Guth L, Yellin H 1971: The dynamic nature of the so-called 'fiber types' of mammalian skeletal muscle. Exp Neurol 31: 277-300

Guth L, Samaha FJ 1970: Procedure for the histochemical demonstration of actomyosin ATPase. Exp Neurol 28: 365-367

Hawkins RR, Moody WG, Kemp JD 1985: Influence of genetic type, slaughter weight and sex on ovine muscle fiber and fat-cell development. J Anim Sci 6: 1154-1163

Henkel P 1991: Can meat quality be assessed histochemically? Dev Anim Vet Sci 25: 212

Maltin C, Balcerzak D, Tilley R, Delday M 2003: Determination of meat quality: tenderness. Proc Nutr Soc 62: 337-347

McCoard SA, McNabb WC, Birtles MJ, Harris PM, McCutgheon SN, Peterson SW 2001: Immunohistochemical detection of myogenic cells in muscles of fetal and neonatal lambs. C Tis Org 169: 21-33

Moody WG, Kemp JD, Mahyuddin M, Johnston DM, Ely G 1980: Effect of feeding systems, slaughter weight and sex on histological properties of lamb carcasses. J Anim Sci 50: 249-256

Nachlas MM, Tsou KC, De Sonza E, Cheng C, Seligman AM 1957: Cytochemical demonstration of succinic dehydrogenase by the use of a new p-nitrophenyl substituted ditetrazale. J Histochem Cytochem 5: 420-436

Padykula HA, Hermann E 1955: The specificity of the histochemical method for adenosine triphosphatase. J Histochem Cytochem 3: 110-183

Ruttle JL 1971 Influence of Sex and Type of Birth on Performance of Early. J Anim Sci 32: 974-976

Solomon MB, Dunn MC 1988: Simultaneous histochemical determination of three fiber types in single section of Ovine, Bovine and Porcine Skeletal muscle. J Anim Sci 66: 255-264

Solomon MB, Moody WG, Kemp JP, Ely DG 1981: Effect of breed, slaughter weight and sex on histological properties of ovine muscle. J Anim Sci 52: 1019-1021

Suzuki A 1971a: Histochemical classification of individual skeletal muscle fibers in the sheep. I. On M. semitendinosus, M. longissimus dorsi, M. psoas major, M. latissimus dorsi and M. gastrocnemius. Jap J Zootech Sci 42: 39-54

Suzuki A 1971b: Histochemical classification of individual skeletal muscle fibers in the sheep. II. On M. serratus ventralis, M. supraspinatus, M. infraspinatus, M. semimembranosus and M. triceps brachii (Caput longum). Jap J Zootech Sci 42: 463-473

Suzuki A, Cassens RG 1983: A histochemical study of myofiber types in the serratus ventralis thoracis muscle of sheep during growth. J Anim Sci 56: 1447-1458

Suzuki A, Tamate H 1988: Distribution of myofiber types in the hip and thigh musculature of sheep. Anat Rec 221: 494-502 
Velotto S, Di Prisco SMR, Stasi T, Crasto A 2005: Histomorphometrical evaluation of myocyte types in the lamb. Acta Vet Brno 74: 175-182

Whippl G, Koohmaraie M 1992: Effects of lambs age, muscle type, and 24-hour activity of endogenous proteinases on postmortem proteolysis. J Anim Sci 70: 798-804

White NA, McGavin MD, Smith JD 1978: Age-related changes in percentage of fiber types and mean fiber diameters of the ovine quadriceps muscles. Am J Vet Res 39: 1297-1302 
Plate I

Velotto S. et al.: Effect of Age ... pp. 3-11
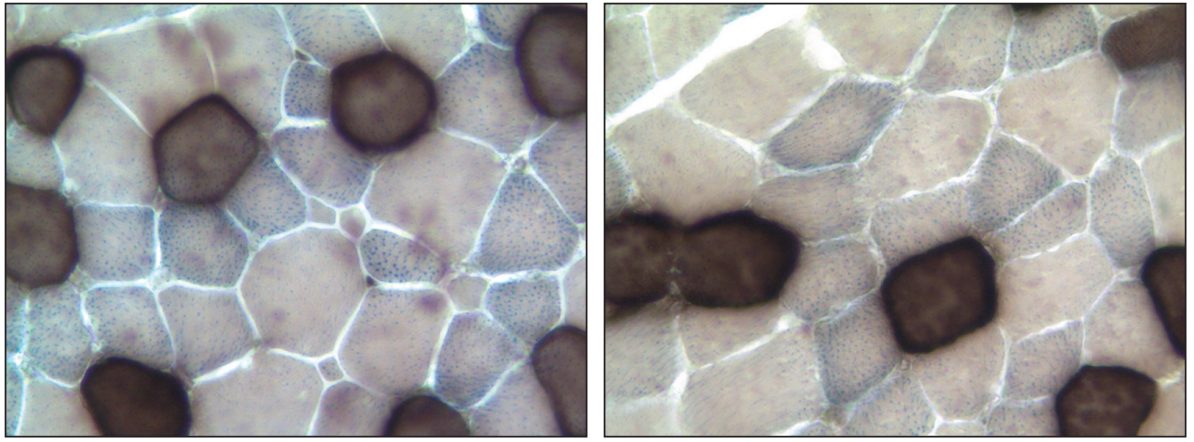

Fig. 1. M. latissimus dorsi -60 days - male - single Fig. 2. M. semitendinosus -60 days - female birth

single birth

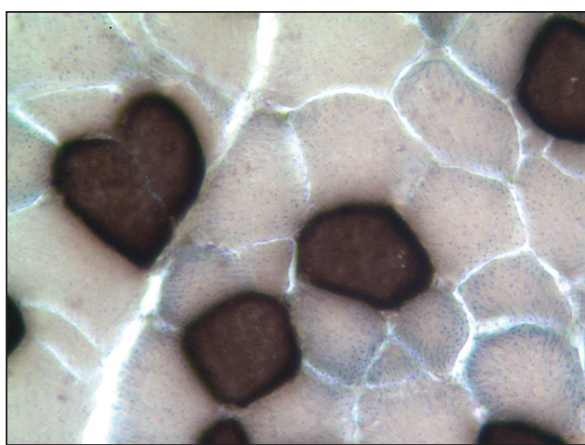

Fig. 3. M. latissimus dorsi - 120 days - male quadruplet birth

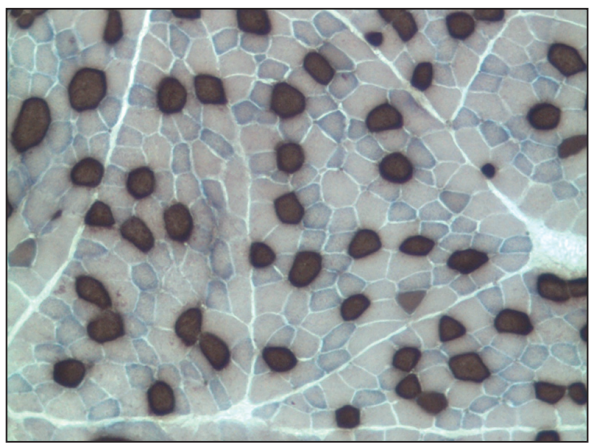

Fig. 5. M. latissimus dorsi - 120 days - \% FOG L. dorsi vs. Semitendinosus

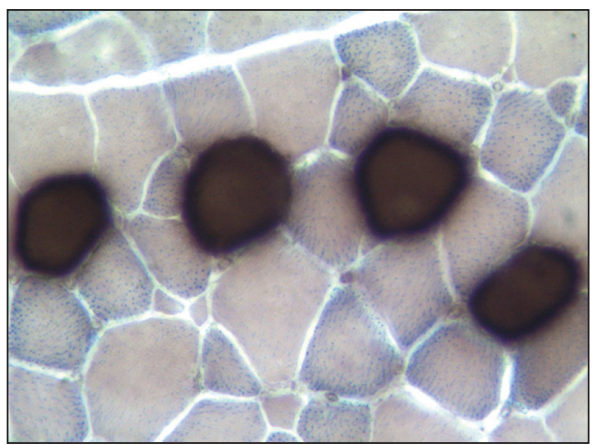

Fig. 4. M. semitendinosus - 120 days - female quadruplet birth

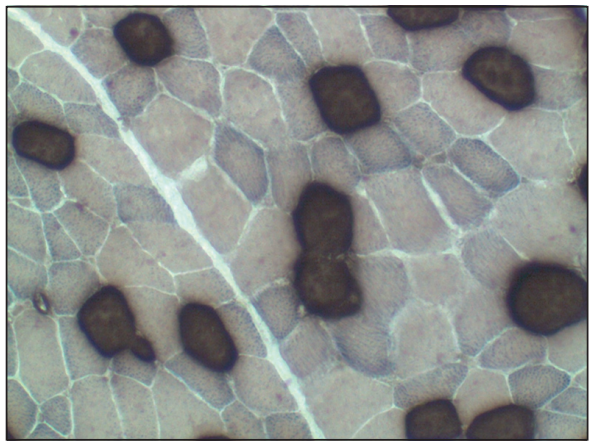

Fig. 6. M. semitendinosus - 120 days - \% FOG L. dorsi vs. Semitendinosus 
Plate II

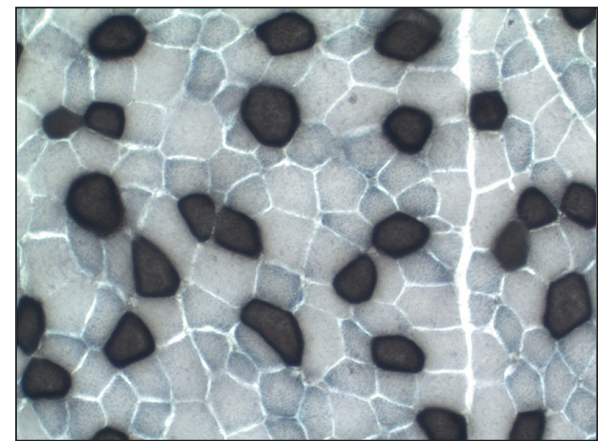

Fig. 7. M. semitendinosus -120 days - $\%$ FOG vs. $\%$ FG vs. $\%$ SO 